\title{
Bisphenol A Induces Apoptosis in Liver Cells through Induction of ROS
}

\author{
Ansoumane Kourouma, Chao Quan, Peng Duan, Suqin Qi, Tingting Yu, \\ Yinan Wang, and Kedi Yang
}

MOE Key Lab of Environment and Health, Department of Occupational and Environmental Health, School of Public Health, Tongji Medical College, Huazhong University of Science and Technology, 13 Hangkong Road, Wuhan 430030, China

Correspondence should be addressed to Kedi Yang; yangkd@mails.tjmu.edu.cn

Received 17 July 2014; Revised 27 October 2014; Accepted 7 January 2015

Academic Editor: Jennifer L. Freeman

Copyright (C) 2015 Ansoumane Kourouma et al. This is an open access article distributed under the Creative Commons Attribution License, which permits unrestricted use, distribution, and reproduction in any medium, provided the original work is properly cited.

Oxidative stress mechanisms are involved in hepatotoxicity. The liver is reported to be affected by bisphenol A (BPA) in animals studies and has been also reported to possess hepatic toxicity. This study aimed to examine association between liver health status and the effects of BPA on the antioxidant defense systems and liver biomarkers. BPA $(0,2,10$, and $50 \mathrm{mg} / \mathrm{kg})$ body weight was mixed in corn oil and intraperitoneally administered every forty-eight hours for 30 days in dose-dependent manner. There was no significant difference between the body weight and weight of rat liver in BPA-treated groups and control groups. The study results show that the levels of malondialdehyde (MDA) and hydrogen peroxide $\left(\mathrm{H}_{2} \mathrm{O}_{2}\right)$ increased after exposure to BPA. However, the antioxidant enzymes catalase (CAT), superoxide dismutase (SOD), and glutathione peroxidase (GSH-PX) were significantly $(P<$ $0.001, P<0.05$, and $P<0.001$, resp.) decreased at $50 \mathrm{mg} / \mathrm{kg}$ dosage. Liver markers activities such as lactate dehydrogenase (LDH), glutamic-oxalacetic transaminase (GOT), and glutamic-pyruvic transaminase (GPT) were significantly increased, while $\gamma$-glutamyl transferase $(\gamma-\mathrm{GT})$ activity was decreased. BPA exposure increased activity of liver biomarkers indicating liver hyperactivity. Analysis of the liver section provided essential evidence of liver apoptosis. Moreover, BPA may lead to induced toxic response of liver oxidative system.

\section{Introduction}

Bisphenol A [2, 2-bis (4-hydroxyphenyl) propane] (BPA) is one of the highest volume chemicals produced worldwide, and human exposure to BPA is thought to be ubiquitous [1]. BPA is suspected to be an endocrine-disrupting chemical, an important component of polycarbonate and epoxy resins. It is mainly found in the composition of a wide variety of polycarbonate plastic, flame retardants, dental sealant resins, and liners for food packaging.

In the last decade, several studies demonstrated the toxicity of BPA even at low doses. Studies have shown that BPA can cause injury in the liver, kidney, brain, epididymal sperm in rodents, and other organs by forming reactive oxygen species (ROS) $[2,3]$. ROS have been shown to play an important role in the defense mechanisms against pathological conditions but excessive generation of free oxygen radicals may damage tissues and also damage proteins, leading to the structural alteration and functional inactivation of many enzymes and receptor proteins involved in cell signaling [4]. However, epidemiological studies of BPA are still subject to controversy. Due to increased concerns over the safety of BPA, its presence has been prohibited in plastic bottles for infants by Health Canada (2009), the European Union (2011), and the US Food and Drug Administration (FDA) (2012) and will be totally abolished in France by 2015 in food containers [5].

BPA toxicities have focused on reproductive effects [68]. Besides its inherent effects on the endocrine system, [9], BPA is also known to inflict oxidative stress by affecting vital organs in humans [10]. Furthermore, some research also showed that the elevated levels of ROS result in oxidation of cellular components with unsaturated fatty acids and else induce cell apoptosis and degeneration [11]. The liver is the major organ for the metabolism and detoxification of xenobiotic, including BPA. Specific estrogen receptor exists in the liver, and cellular responses involving estrogen interactions 
have been identified. In rat, BPA is glucuronidated by liver microsomes and that the glucuronidation is mediated by UGT2B1, an isoform of UDP-glucuronosyltransferase. Glucuronidation is the major metabolic pathway of the chemical, as demonstrated in primary cultures of rat hepatocytes. After glucuronidation, the resultant glucuronide is excreted mainly into the bile in rat male and nonpregnant female [12]. The major excretory conjugate is BPA-glucuronide rather than sulphate, because the sulphate is undetectable in rat urine after the oral administration of BPA [13]. ROS are scavenged by the endogenous antioxidant defense system, including superoxide dismutase (SOD), catalase (CAT), and reduced glutathione (GSH-Px) in cells. The phenolic compound such as BPA is known to cause abnormalities, DNA damage, and genotoxicity [14] in the liver of rats and mice [3].

Therefore, it has been established that the early environmental stress during developmental stages could cause persistent changes in mitochondrial activity of nonhuman primates [15], which highlights the influence of early exposure for development of disease later in life. Taken together, these findings above lead us to hypothesize that early BPA exposure may affect the susceptibility of liver injury in adulthood. Manifestation by apoptosis in liver tissues and related ROS generations in the process are yet to be determined. Lee et al. reported that urinary concentration of BPA was associated with abnormal liver function in human [16]. A recent crosssectional human study of 1455 Americans demonstrated a statistically significant association between higher BPA concentrations and abnormal concentrations of the liver enzymes, that is, $\gamma$-glutamyl transferase $(\gamma$-GT), alkaline phosphate (ALP), and lactate dehydrogenase (LDH) [17]. In addition, BPA can cause apoptosis by the induction of adenylate kinase activation, TNF-alpha gene expression [18], and dysregulation of $\mathrm{Ca}^{2+}$ homeostasis, ROS [19]. However, the mechanisms of the adverse effect of BPA on liver function abnormality and apoptosis are not yet completely understood. The purpose of the present study was to evaluate the relationship between BPA exposures and suggest possible mechanisms for liver hyperactivity, such as oxidative stress and direct apoptosis in liver tissues.

\section{Materials and Methods}

2.1. Chemicals and Reagents. Bisphenol A (2,2-Di (4hydroxyphenyl) propane) was purchased from DR Co. (Augsburg, Germany, purity: 98.5\%). Corn oil was obtained from Sigma-Aldrich (St. Louis, MO, USA). Sigma Chemical Co. (St Louis, MO) USA, Collagenase, Trypsin-EDTA were obtained from GIBCO (Grand Island, NY, USA). Sodium lauryl sulphate from SRL, Eosin stain and Hematoxylin stain were obtained from HiMedia (Mumbai). LDH, GOT, GPT, $\gamma$-GT, CAT GSH-Px, SOD, H2O2 and MDA assay kit (Jiancheng Bioengineering Ltd., Nanjing, China). All other chemicals are of analytical grade.

2.2. Animals and Treatments. Twenty-four healthy male Sprague-Dawley rats (50 days old) were purchased from the Tongji Medical College Animal Laboratory (Wuhan, China).
The animals were housed in plastic cages under a wellregulated light and dark schedule ( $12 \mathrm{~h}$ light: $12 \mathrm{~h}$ dark) at $24 \pm 3^{\circ} \mathrm{C}$, humidity $(50 \pm 5 \%)$ environment, and free access to chow and tap water ad libitum. The doses and time used for the present study were derived from published data $[20,21]$ and the result of our preliminary experiment. The rats were randomly divided into four groups, each group containing six rats. Each group was fed different doses of bisphenol A $(0,2,10$, and $50 \mathrm{mg} / \mathrm{kg})$ body weight, respectively, in corn oil every forty-eight hours by intraperitoneal injection for 30 days. After 30 days of treatment, the rats were sacrificed. Ethical clearance for the use of animals in the study was obtained from the Institutional Animal Ethics Committee prior to the initiation of the study, and the experiments were performed in accordance with the guidelines for the Care and Use of Laboratory Animals published by Ministry of Health of China (Approval ID: 2011-s2456).

2.3. Necropsy. Twenty-four hours after the last dose, the animals were sacrificed; liver was removed cleaned from adhering fat and connective tissues and weighed. The liver was quickly frozen at $-70^{\circ} \mathrm{C}$ for later use for biochemical assays.

2.4. Enzyme Extraction and Assay. The liver was homogenized using lysis buffer (containing $1 \mathrm{mM} \mathrm{Na}_{2}$ EDTA, $150 \mathrm{mM}$ $\mathrm{NaCl}, 10 \mathrm{mM}$ PMSF, $10 \mathrm{mM}$ Tris, $1 \mathrm{mM}$ Aprotinin) to evaluate oxidase stress following the protocol of assay kit (Jiancheng Bioengineering Ltd., Nanjing, China). All operation was done at $4^{\circ} \mathrm{C}$. Protein concentrations were determined using a $\mathrm{BCA}$ kit (Pierce, Rockford, USA) that employed serum albumin as a standard.

2.5. Marker Enzymes. Lactate dehydrogenase (LDH) activity was measured using a-ketovaleric acid as the substrate [22]. $\gamma$-Glutamyl transferase ( $\gamma$-GT) was measured by the method of [23]. The activities of glutamic-oxalacetic transaminase (GOT) and glutamic-pyruvic transaminase (GPT) were assayed according to the method that is usually used in clinical examination [24].

2.6. Reactive Oxygen Species. Hydrogen peroxide $\left(\mathrm{H}_{2} \mathrm{O}_{2}\right)$ production was quantified by the method of [25]. In brief, $0.1 \mathrm{~mL}$ liver extract was added to an assay mixture containing $\mathrm{KCL}(1.13 \mathrm{M}), 0.1 \mathrm{~mL}$ potassium phosphate $(150 \mathrm{mM})$, $0.05 \mathrm{~mL} \mathrm{MgCl}_{2}(60 \mathrm{mM}), 0.05 \mathrm{~mL}$ EDTA $(8 \mathrm{mM}), 0.1 \mathrm{~mL}$ Tris- $\mathrm{HCl}(200 \mathrm{mM}, \mathrm{pH} 7.4)$, and $0.1 \mathrm{~mL}$ acetylated ferrocytochrome $c(1 \mathrm{mM})$. The oxidation of ferrocytochrome $c$, which provides a measure of $\mathrm{H}_{2} \mathrm{O}_{2}$ production, was then evaluated at $550 \mathrm{~nm}$, in a spectrophotometer. The $\mathrm{H}_{2} \mathrm{O}_{2}$ content of the sample was expressed as $\mu \mathrm{mol} / \mathrm{min} / \mathrm{mg}$ protein.

2.7. Lipid Peroxidation (LPO). Lipid peroxidation (LPO) was determined by the procedure of [26]. Malondialdehyde (MDA), formed as an end product of the peroxidation of lipids, served as an index of the intensity of oxidative stress. MDA reacts with thiobarbituric acid to generate a color 
TABLE 1: Body weight $(\mathrm{g})$ and selected absolute $(\mathrm{g})$ and relative organ weight $(\mathrm{mg} / \mathrm{g})$ of male rats in control and treatment groups.

\begin{tabular}{|c|c|c|c|c|}
\hline \multicolumn{5}{|c|}{ Doses of BPA (mg/kg b.wt./day) } \\
\hline & Control & $2 \mathrm{mg}$ & $10 \mathrm{mg}$ & $50 \mathrm{mg}$ \\
\hline Initial body weight (g) & $98.46 \pm 9.85$ & $83.28 \pm 7.98$ & $88.88 \pm 9.25$ & $92.95 \pm 7.37$ \\
\hline Final body weight (g) & $218.58 \pm 15.75$ & $200.91 \pm 11.49$ & $204.74 \pm 11.36$ & $212.14 \pm 22.95$ \\
\hline \multicolumn{5}{|l|}{ Liver } \\
\hline Absolute (g) & $7.72 \pm 0.56$ & $7.09 \pm 0.54$ & $7.18 \pm 0.51$ & $7.39 \pm 0.87$ \\
\hline Relative (mg) & $35.34 \pm 1.58$ & $35.39 \pm 2.85$ & $35.06 \pm 1.15$ & $34.88 \pm 1.39$ \\
\hline
\end{tabular}

Values are expressed as mean $\pm \mathrm{SD}, n=6$. The symbol represents statistical significance (ANOVA) from control: ${ }^{*} P<0.05$.

product that can be measured optically at $532 \mathrm{~nm}$. The level of MDA was expressed as nmol MDA per milligram protein.

2.8. Enzymatic Antioxidants. The activity of catalase (CAT) was assayed by the method of [27]. In this method, dichromate in acetic acid is reduced to chromic acetate when heated in the presence of $\mathrm{H}_{2} \mathrm{O}_{2}$, with the formation of perchloric acid as an unstable intermediate. The chromic acetate thus produced is measured colorimetrically at $610 \mathrm{~nm}$. Superoxide dismutase (SOD) was assayed according to the method of [28]. The unit of enzyme activity is defined as the enzyme required for $50 \%$ inhibition of pyrogallol autooxidation. Glutathione peroxidase (GSH-Px) activities were assayed by method of [29] quantifying the rate of oxidation of the reduced glutathione to the oxidized glutathione by $\mathrm{H}_{2} \mathrm{O}_{2}$. One unit of GSH-Px was defined as the amount that reduced the level of GSH by $1 \mu \mathrm{M}$ in $1 \mathrm{~min} / \mathrm{mg}$ protein, at $412 \mathrm{~nm}$ absorbance.

2.9. Apoptosis Assay with TUNEL Staining. To detect apoptotic cell death, paraffin embedded sections were stained by the TUNEL technique using an in situ apoptosis detection kit (Wuhan Boster Biological Technology, Ltd., Wuhan, China) according to the instructions provided by the manufacturer. The sections were deparaffinized with xylene, rehydrated, and treated with $200 \mu \mathrm{g} / \mathrm{mL}$ proteinase $\mathrm{K}$ for $15 \mathrm{~min}$ at room temperature. Endogenous peroxidase was inactivated by covering the sections with $3 \% \mathrm{H}_{2} \mathrm{O}_{2}$ in $\mathrm{H}_{2} \mathrm{O}$ for 5 min at room temperature. End-labeling was achieved by catalytically adding residues of digoxigenin-labeled 11-dUTP and dATP to the $3^{\prime}$-hydroxyl ends of DNA with the enzyme TDT. The reaction buffer containing dUTP, dATP, and TDT was applied for $60 \mathrm{~min}$ at $37^{\circ} \mathrm{C}$ in a humid atmosphere. The digoxigenin was detected immunohistochemically with a digoxigeninspecific peroxidase-conjugated antibody (30 $\mathrm{min}$ in a humid atmosphere at room temperature). For the color reaction, metal-enhanced diaminobenzidine was used as substrate. The sections were counterstained with hematoxylin. Positive and negative control sections were included in each sample. And the apoptotic cells were identified based on intense brown nuclear staining and observed under light microscope (IX-71, Olympus, Tokyo, Japan). The data were expressed as the average of apoptotic cell numbers per sample. Apoptotic cells were identified by their brownish staining. The whole area of the section was scanned with the high-power magnification (400x). The apoptotic index was then calculated as follows: $\mathrm{AI}=$ (number of apoptotic cells per section/total number of cells per section) $\times 100 \%$.

2.10. Statistical Analysis. All values are expressed (mean \pm SD, $n=6)$ and were compared by one way analysis of variance (ANOVA) followed by the Tukey-Kramer multiple comparison test. All statistical analyses were carried out using SPSS statistical package 17.0 (SPSS Inc., Chicago, IL, USA) and GraphPad Prism software version 5.0 (San Diego, USA) was used to determine whether the results of treatments were significantly $(*$ for $P<0.05)$ or extremely significantly $(* *$ for $P<0.01$ and $* * *$ for $P<0.001)$ different from the control groups without BPA.

\section{Results}

3.1. Body and Liver Weight. At the beginning of the experiment, rats from different groups showed approximately similar body weight values. The treatment of BPA promoted an increase in the body weight gain when compared to the initial weight of rats. The final body weight of animals from these groups was not statistically different from values from untreated animals (Table 1). However, no significant changes between rat liver absolute and relative weight of BPA-treated groups were observed.

3.2. Reactive Oxygen Species and Lipid Peroxidation. The effect of BPA treatment on reactive oxygen such as hydrogen peroxide $\left(\mathrm{H}_{2} \mathrm{O}_{2}\right)$ in rat liver is presented in Figure 1(a). BPA treatment significantly increased $\mathrm{H}_{2} \mathrm{O}_{2}$ at concentration of $50 \mathrm{mg} / \mathrm{kg} /$ day $\left(3.06,{ }^{* *} \mathrm{P}<0.01\right)$. Lipid peroxidation index in rat liver (MDA) was significantly increased (3.01 and 3.19, resp.; $\left.{ }^{* *} P<0.01\right)$ in response to BPA 10 and $50 \mathrm{mg} / \mathrm{kg} /$ day as compared to the corresponding control (Figure 1(b)).

3.3. Enzymatic Antioxidants. The activities of the liver antioxidants CAT $(10.23,5.83$, and 4.32, resp.) and GSH-Px (1.28, 0.63 , and 0.47 , resp.) were significantly decreased in a dose-dependent manner in response to BPA treatment as compared to the corresponding control (Figures 2(a) and $2(c))$. However, SOD $(14.16,12.36$, and 10.41, resp.) was only changed in the highest dose (Figure 2(b)). Animals treated with $50 \mathrm{mg} / \mathrm{kg} /$ day of BPA showed significant decrease as compared to the corresponding control in the case the activity of CAT, GSH-Px $\left({ }^{* * *} P<0.001\right)$, and SOD $\left({ }^{*} P<0.05\right)$, respectively. 


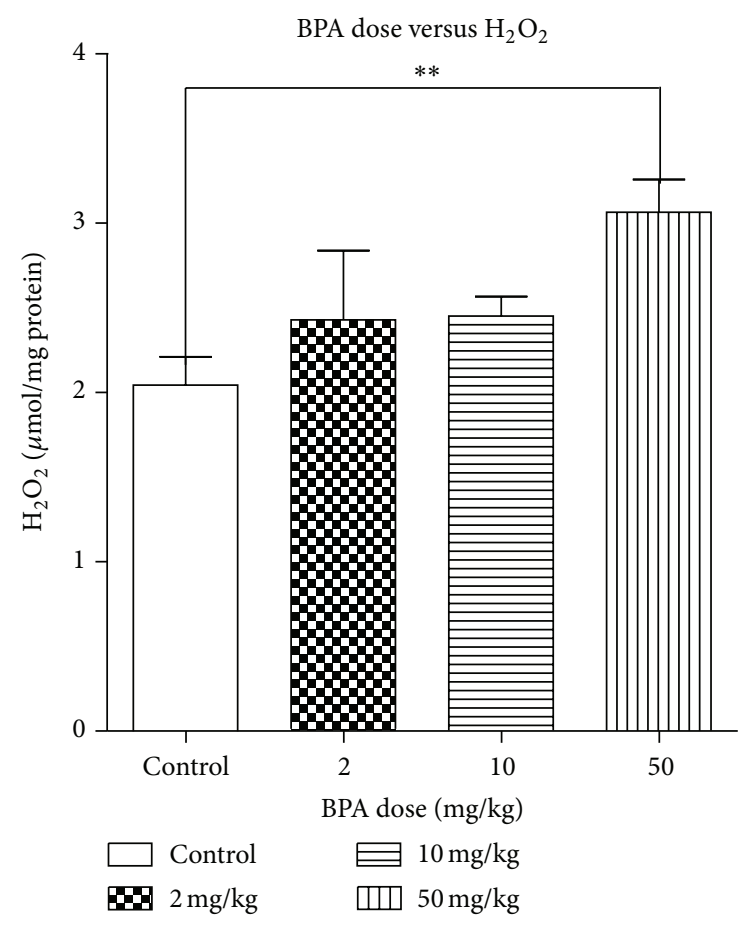

(a)

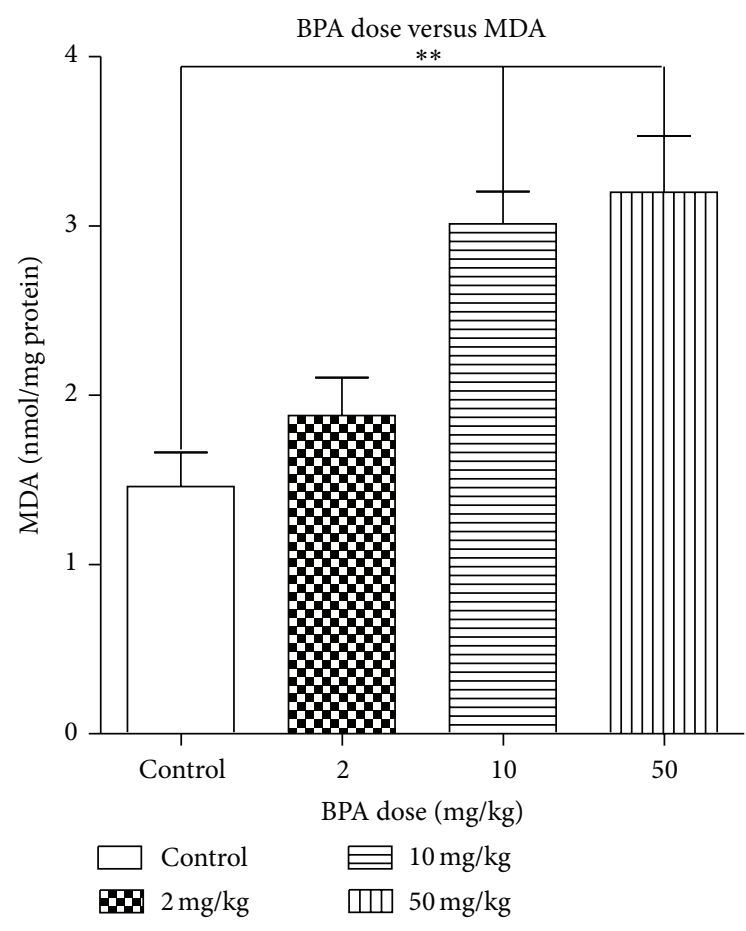

(b)

Figure 1: (a) Effect of BPA on $\mathrm{H}_{2} \mathrm{O}_{2}$ levels ( $\mu \mathrm{mol} / \mathrm{mg}$ of protein) in the liver of rats. (b) Effect of BPA on MDA levels (nmol/mg of protein) in the liver of rats. Values are expressed as mean $\pm \mathrm{SD}, n=6$. The symbol represents statistical significant (ANOVA) from control: ${ }^{* *} P<0.01$.

3.4. Assay of Liver Function. Several main biochemical parameters of liver function in liver tissue are assayed to further investigate the effect of BPA on the liver of rat.

3.4.1. Marker Enzymes. The activities of the liver markers enzymes like glutamic-oxalacetic transaminase (GOT) (144.27, 282.78, and 347.09, resp.), glutamic-pyruvic transaminase (GPT) (116.64, 139.61, and 202.71, resp.), and lactate dehydrogenase (LDH) (171.11, 181.33, and 186.18, resp.) were significantly increased in response to BPA treatment groups as compared to the corresponding control at 10 and $50 \mathrm{mg} / \mathrm{kg} /$ day (Figures 3(a), 3(b), and 3(c)). Activities of GOT were extremely increased at 10 and $50 \mathrm{mg} / \mathrm{kg} / \mathrm{day}\left({ }^{* * *} P<\right.$ 0.001). Activities of GPT were also increased significantly at 10 and $50 \mathrm{mg} / \mathrm{kg} /$ day $\left({ }^{* *} P<0.01,{ }^{* * *} P<0.001\right.$, resp.).

3.4.2. $\gamma$-Glutamyl Transferase $(\gamma$-GT). The activities of liver $\gamma$-GT $(2.40,1.26$, and 1.13 , resp.) were significantly decreased in response to BPA treatment groups as compared to the corresponding control at 2,10 , and $50 \mathrm{mg} / \mathrm{kg} / \mathrm{day}\left({ }^{*} P<0.05\right.$, ${ }^{* *} P<0.01$, and ${ }^{* * *} P<0.001$, resp.) (Figure $3(\mathrm{~d})$ ).

3.5. In Situ Apoptotic Cells Detection (TUNEL). The TUNEL results of each group are shown in Figure 4 . The light microscopic evaluation of the control group revealed characteristic appearance of normal hepatic tissue (Figure 4(a)). However, BPA-treated showed that the number of apoptotic cells was significantly increased (46.72\%, 32.24 and $15.08 \%)$, respectively, in response to $\mathrm{BPA} 2,10$, and $50 \mathrm{mg} / \mathrm{kg} /$ day in the liver compared with the control group (5.07\%). In contrast, no TUNEL positive cells were seen in control group. Observed histological changes in liver tissues have shown a dose-dependent increase (Figure 4(e)).

\section{Discussion}

The present research aimed to evaluate whether exposure to BPA induces oxidative stress in the liver of male rats and its contribution to liver diseases. The issue of the effect of graded doses of BPA on liver disease is currently controversial. In the present study, BPA was administered intraperitoneally in corn oil every forty-eight hours for 30 days on male SpragueDawley (SD) rats. Body weight and the weight of liver in BPA-treated rats did not show significant differences when compared to the control group.

Interestingly, the liver tissues antioxidant enzymes evaluation seems to have important role in the etiology of ROS and liver damage. The present work shows that the increased hydrogen peroxide $\left(\mathrm{H}_{2} \mathrm{O}_{2}\right)$ and lipid peroxidation (LPO) are accompanied by concomitant decrease in the activities of antioxidant enzymes, namely, CAT, GSH-Px, and SOD. In accordance with our finding, $\mathrm{Wu}$ et al. demonstrated significant decrease in the levels of GSH and SOD in BPAtreated group; this decrease may indicate liver tissues damage [30].

LPO is one of the main manifestations of oxidative damage initiated by ROS and it has been linked to the altered membrane structure and enzyme inactivation and excessive 


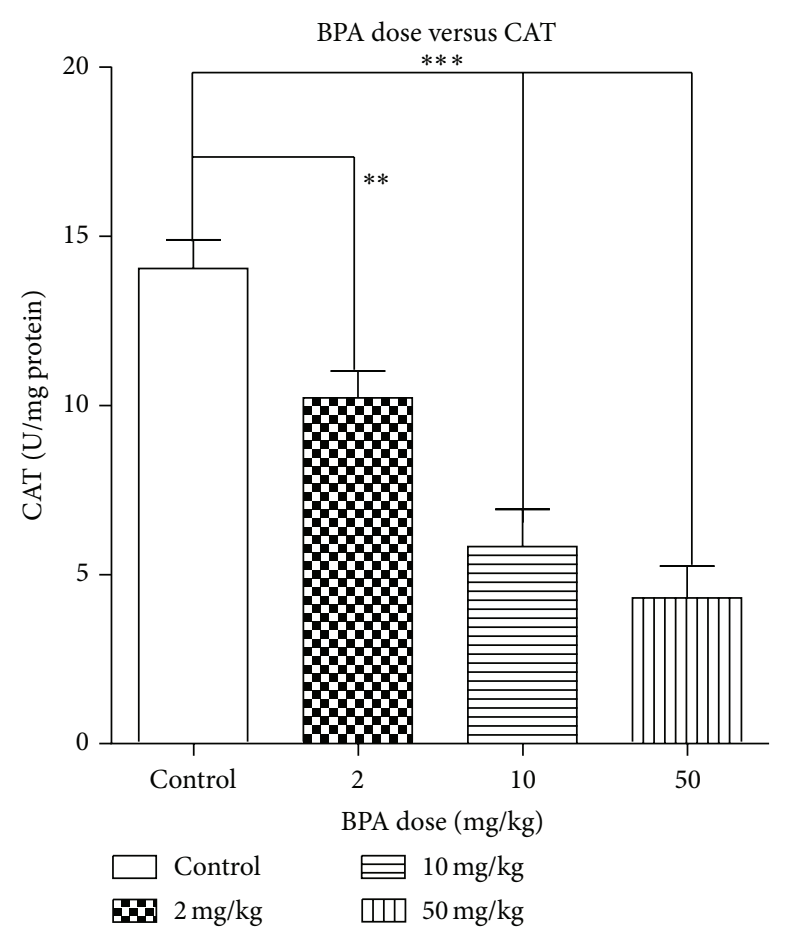

(a)

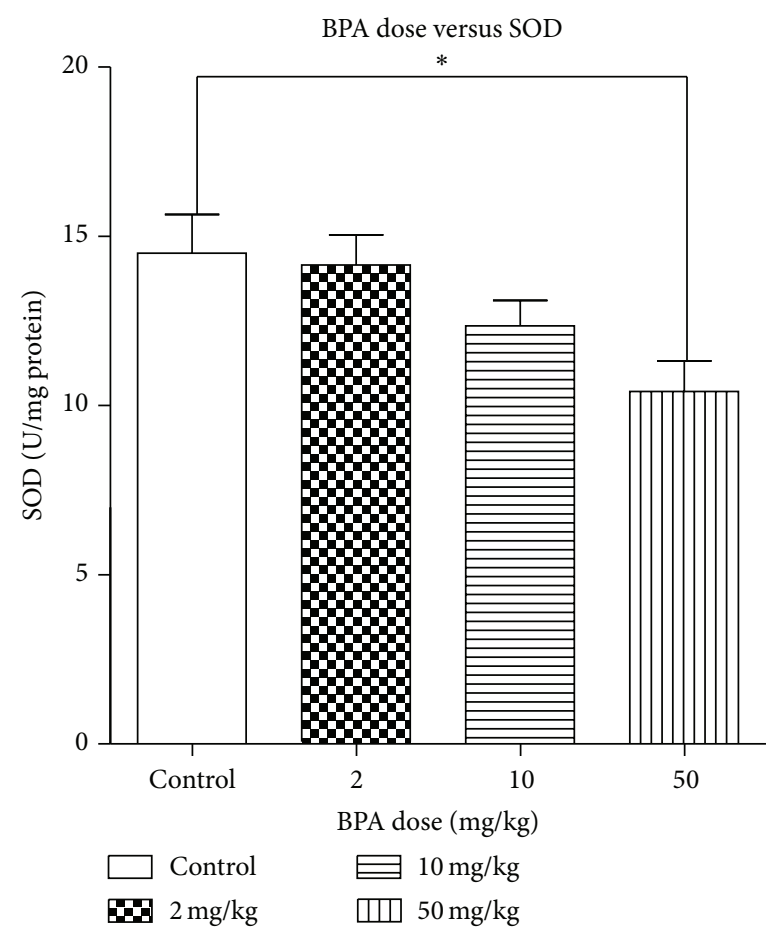

(b)

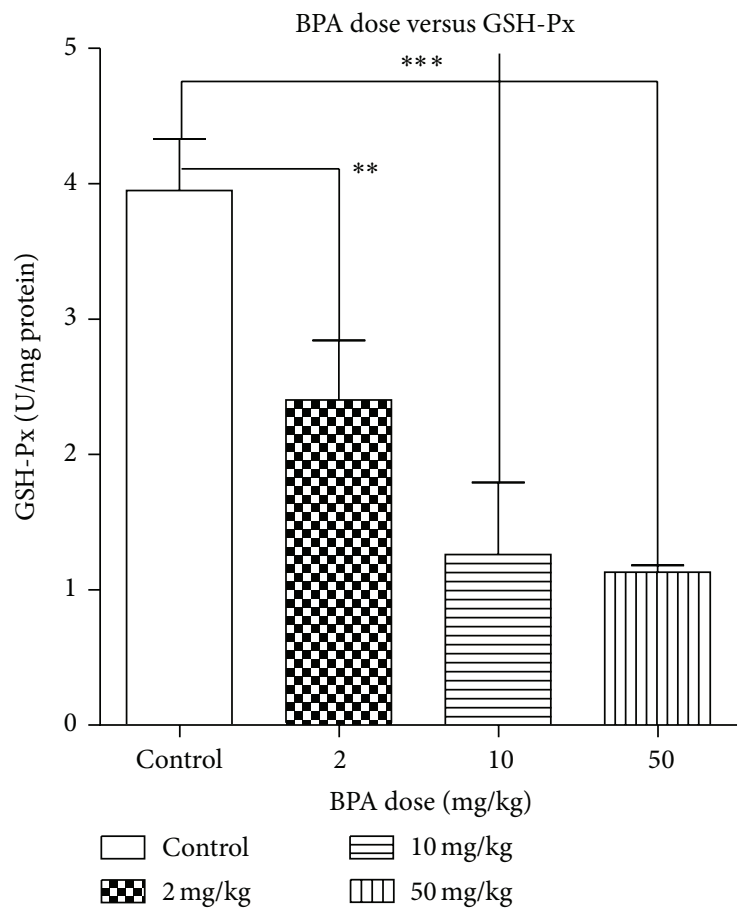

(c)

FIGURE 2: (a) Effect of BPA on CAT activities (U/mg of protein) in the liver of rats. (b) Effect of BPA on SOD activities (U/mg of protein) in the liver of rats. (c) Effect of BPA on GSH-Px activities (U/mg of protein) in the liver of rats. Values are expressed as mean \pm SD, $n=6$. The symbol represents statistical significance (ANOVA) from control: ${ }^{*} P<0.05,{ }^{* *} P<0.01$, and ${ }^{* * *} P<0.001$.

damage of cellular macromolecules (protein, lipids, and nucleic acids) has been shown to be a major contributor to the toxicity of contaminants [31]. The increase in LPO reported here may be the result of increased production of free radicals and/or a decrease in antioxidant status. The decrease in activities of the antioxidant enzymes might predispose the liver to increased free radical damage, because CAT and GSH-Px have been considered the primary scavengers of 


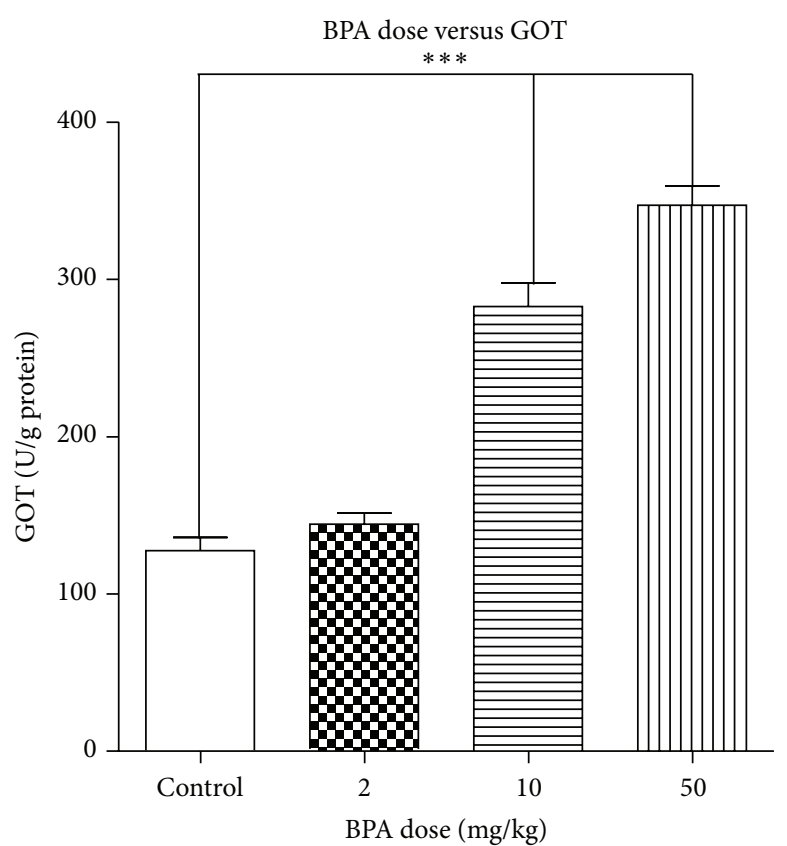

(a)

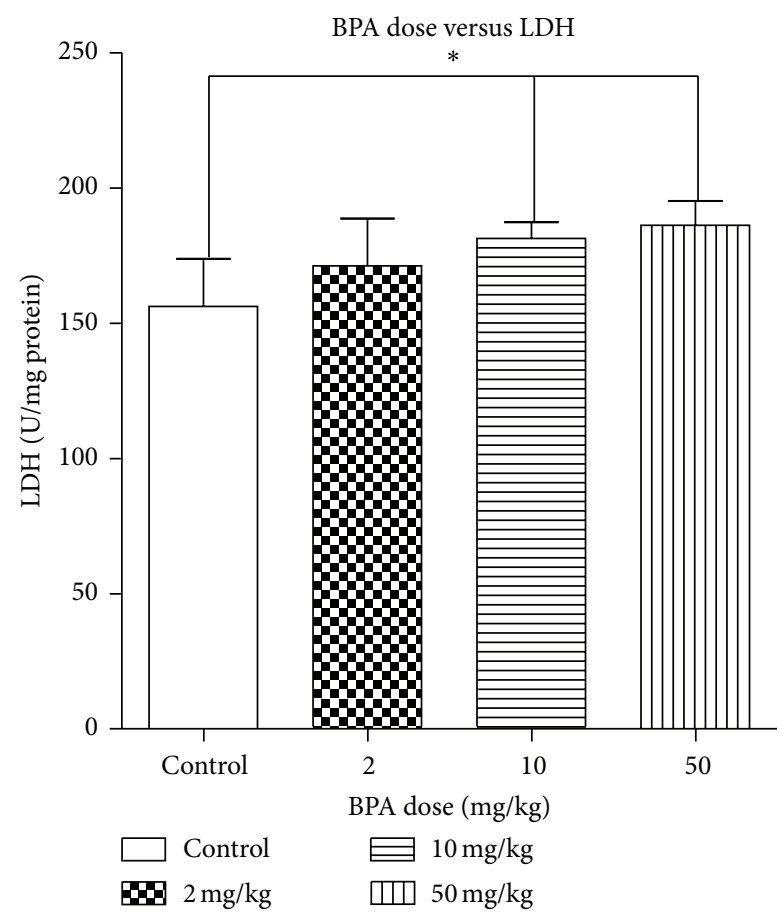

(c)

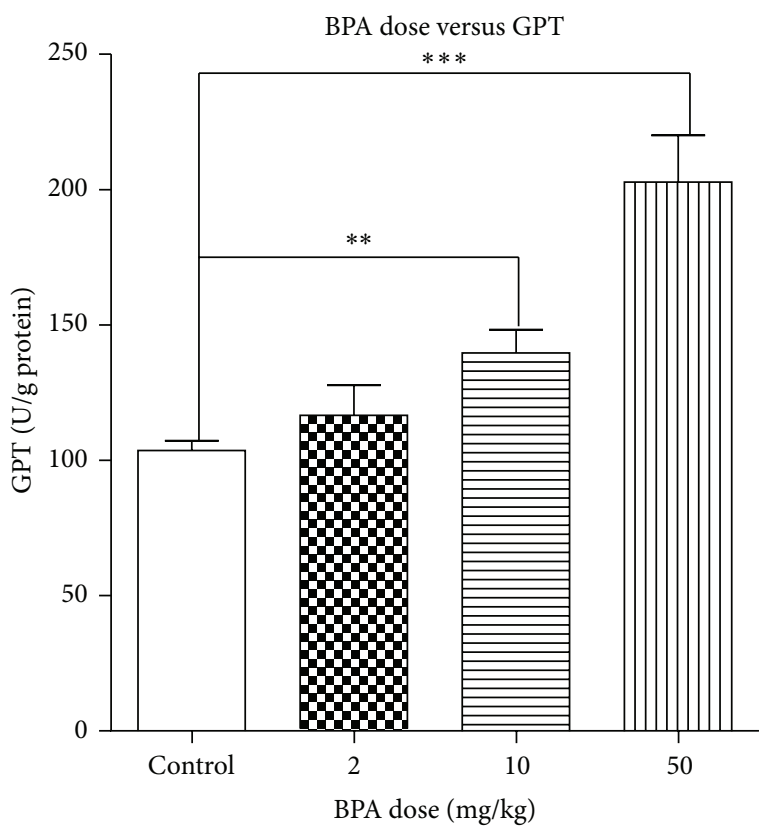

(b)

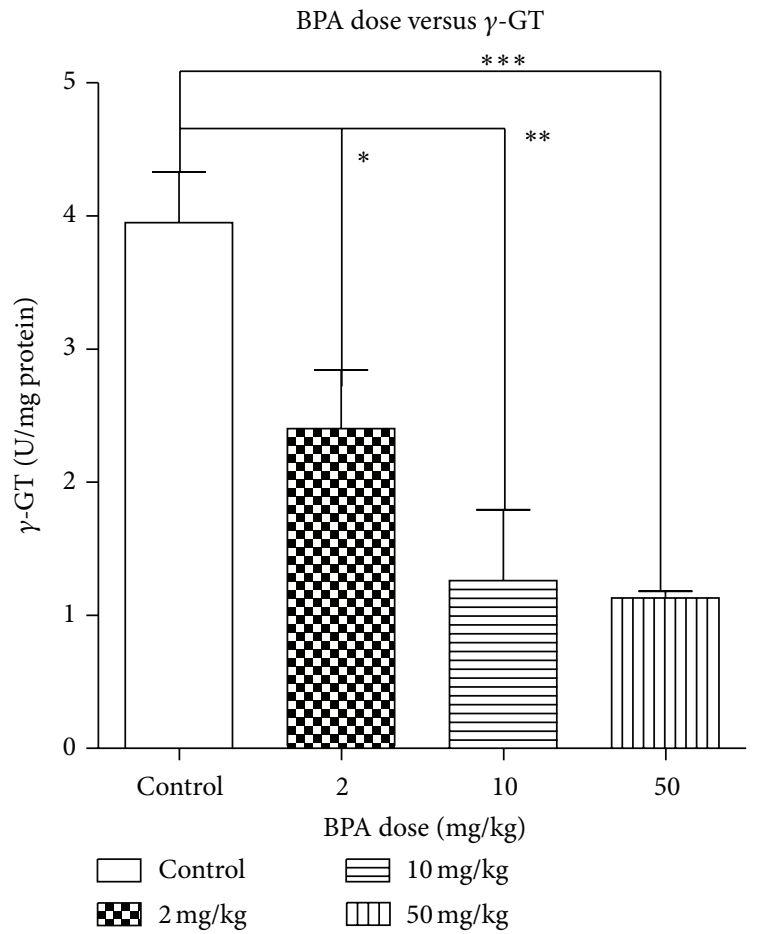

(d)

FIGURE 3: Effect of BPA on liver biomarkers. (a) Effect of BPA on GOT activities (U/g of protein) in the liver of rats. (b) Effect of BPA on GPT activities (U/g of protein) in the liver of rats. (c) Effect of BPA on LDH activities in (U/mg of protein) the liver of rats. (d) Effect of BPA on $\gamma$-GT activities (U/mg of protein) in the liver of rats. Values are expressed as mean $\pm \mathrm{SD}, n=6$. The symbol represents statistical significance (ANOVA) from control: ${ }^{*} P<0.05,{ }^{* *} P<0.01$, and ${ }^{* * *} P<0.001$.

$\mathrm{H}_{2} \mathrm{O}_{2}$ [32]; $\mathrm{SOD}$ can catalyse decomposition of superoxide radicals to produce $\mathrm{H}_{2} \mathrm{O}_{2}$. However, in absence of adequate CAT or GSH-Px activity to degrade $\mathrm{H}_{2} \mathrm{O}_{2}$, more $\mathrm{H}_{2} \mathrm{O}_{2}$ could be converted to toxic hydroxyl radicals and may contribute to the oxidative stress of BPA. In our findings, SOD activities in the liver were accompanied by the decreased CAT activities. The possible explanation for this observation is that the metabolism of BPA mainly occurs in the liver. Hence it 


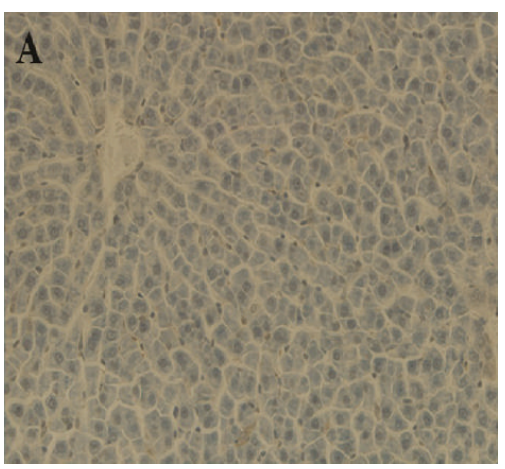

(a)

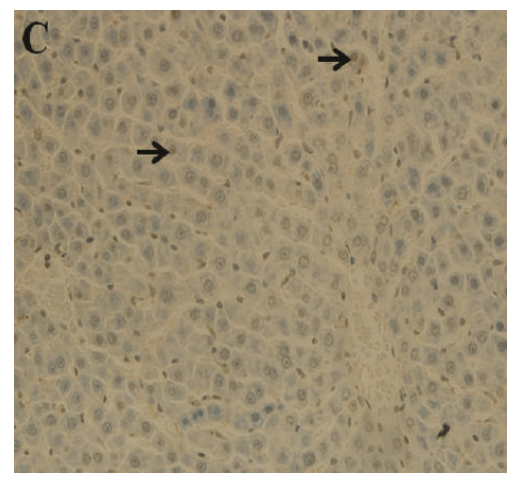

(c)

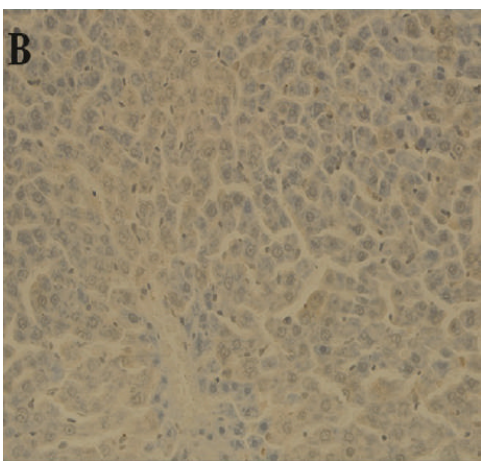

(b)

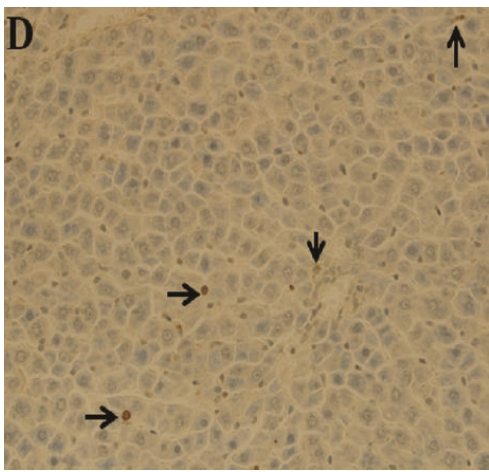

(d)

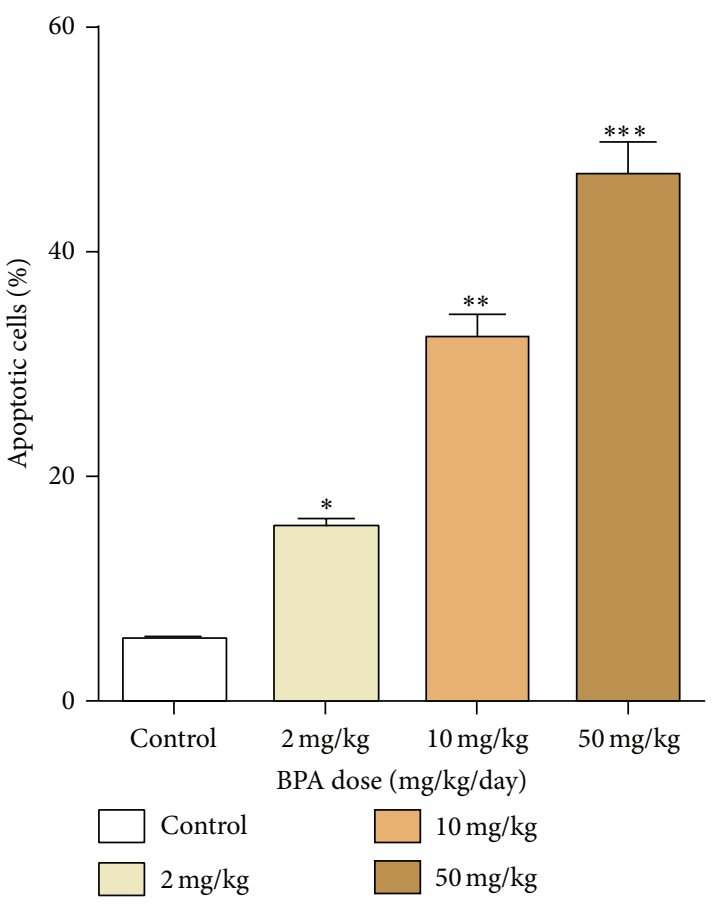

(e)

FIGURE 4: Slide was counterstained with hematoxylin and viewed under a light microscope. Detection of apoptosis TUNEL assay in the liver tissue of rats. The presence of apoptosis after treatment with 2,10 , and $50 \mathrm{mg} / \mathrm{kg} / \mathrm{b} \cdot \mathrm{wt}$ of BPA by intraperitoneal injection for 30 days is shown in panel (a). Brown color reaction indicates cells that underwent apoptosis, as the arrows indicate. Quantitative results of the experiment shown in (a), (b), (c), and (d) are depicted in (e) (the graph representing average number of TUNEL-positive cells in each group). Cells were photographed at the 400x magnification. Apoptotic index of liver (\%). The symbol represents statistical significant (ANOVA) from control: ${ }^{*} P<0.05,{ }^{* *} P<0.01$, and ${ }^{* * *} P<0.001$. Values are represented as the mean $\pm \mathrm{SD}$, and $n=6$ for all groups. 
is glucuronidated by liver microsomes [33], and that glucuronidation was mediated by UGT2B1, an isoform of UGT in rat liver. The metabolites of BPA produced by microsomal Cytochrome P450s showed the enhanced estrogenic activity such as DNA adduct formation with BPA metabolites [34]. Meanwhile, the mechanisms by which SOD-2 can lead to increased cell death have been reported [35]. Also another mechanism for SOD-2 induced apoptosis is through its ability to activate $\mathrm{p} 53$ by production of $\mathrm{H}_{2} \mathrm{O}_{2}$ [36].

Our study indicates that BPA may exert liver hyperactivity by oxidative stress involving apoptosis. Liver function test generally evaluates the presence of liver damage or disease. These tests may include $\gamma$-GT, LDH, GOT, and GPT. Furthermore, the biochemical study showed a decrease on $\gamma$-GT activities and increase on LDH, GOT, and GPT may be due to stimulation of hepatic activity [17]. Moreover, increased liver LDH concentration is most often a good marker of necrosis in tissues. LDH is considered a general marker of tissue damage, although certain isoforms (LDH- 4 and LDH5) are more specific to liver or muscle disease. When the liver is damaged they are released in the bloodstream [37]. GOT and GPT are commonly measured clinically as a marker for the liver function; thus the increased GOT and GPT activities in the liver tissue after exposure to BPA in 30 days indicated that gradual dose of BPA could lead to the liver function abnormality [38]. The marked decrease in the activity of $\gamma$ GT in BPA-treated rats indicates a disruption of the regulated mechanism resulting in metabolism disorders and impaired functions of sertoli cells [39]. Thus, it is possible to say that BPA promotes ROS and induced damage in the liver of male rats.

In our present study, we conducted histopathological examination of liver tissues, oxidative stress index, and liver function tests of all treatment groups. BPA-treated groups had marked defects in morphology; it was observed that the liver brown color reaction indicates cells that underwent apoptosis. Moreover, these can quite easily be distinguished from apoptotic cells on morphological grounds, particularly because DNA is broken at late stages of necrosis [39] when morphological alterations are unambiguous (Figure 4). These observations may be explained by BPA-induced apoptosis in the liver cell. A greater extent of hepatocytes apoptosis seen in the liver sections from the BPA-treated rats also supported this conclusion.

Whereas apoptosis can be set off by several different stimuli, apoptotic signaling within the cell is transduced mainly via two defined molecular pathways: the death receptor pathway (extrinsic pathway) and the mitochondrial pathway (intrinsic pathway) [40]. The intrinsic pathway is triggered by different extra- or intracellular signals, such as irradiations, oxidative stress, toxins, reactive intermediates of xenobiotic metabolism such BPA, and some chemotherapeutic drugs which induce mitochondrial dysfunction [41]. Mitochondrion functions as controllers of the intrinsic apoptotic pathway of cellular apoptosis and is regulated by the $\mathrm{Bcl}-2$ family proteins, resulting in the release of cytochrome $\mathrm{C}$ and other proapoptotic effectors into the cell cytosol ultimately leading to cell death [42]. Cytochrome $c$ release from the mitochondria into the cytosol plays an important role in the regulation of cellular apoptosis and it has been shown to be released through Bax channels [43].

Our study demonstrated that high dose of BPA not only increases the free radical formation but also decreases its ability to detoxify ROS. So, high dose of BPA induces formation of superoxide radicals and peroxynitrite may cause tissue damage leading to increase in the levels of LPO. As a result, activated caspases induce apoptotic signals, leading to apoptosis and hepatotoxicity in liver tissue.

There is increasing evidence that BPA is a toxic compound. However, the degree of toxicity depends on the dose, time, frequency, individual differences, and age of exposure. The present study may merit discussion. The study design with repeated measurements of serum biomarkers for each treatment provides a good opportunity to evaluate the effects of changes in BPA concentrations on liver function and damage over time followed by a histopathological study. Moreover, BPA increased the activities of the liver biomarker enzymes such as LDH, GOT, and GPT and enhanced ROS generation and LPO. However, it depletes the antioxidant enzymes such as CAT, GSH-Px, SOD, and $\gamma$-GT as liver marker.

In conclusion, the present study provides insight into the mode of action of BPA-induced toxicity in the rat liver. Therefore, our present study is worthwhile and warrants further investigations to elucidate the pathways involved in the increased activity of liver biomarkers, hence liver hyperactivity. Analysis of the liver section provided essential evidence of liver apoptosis. Thus, BPA may disrupt the liver, stimulating damage to it by oxidative stress and apoptosis.

\section{Conflict of Interests}

The authors declare that there is no conflict of interests regarding the publication of this paper.

\section{Acknowledgments}

The authors thank Professor Yang Kedi for the helpful advice and guidance on this study and all the staff of Department of Occupational and Environmental Health and Ministry of Education Key Lab for Environmental and Health, School of Public Health (Tongji Medical College), Huazhong University of Science and Technology, China, for providing various resources. This work was supported by grants from the National Natural Science Foundation of China (30972436 and 81172623). They also appreciated helpful comments from Professor Jennifer L. Freeman and anonymous reviewers. Special thanks go to Mr. Abdelrahman Ahmed for improving the quality of the paper.

\section{References}

[1] L. N. Vandenberg, C. M. Schaeberle, B. S. Rubin, C. Sonnenschein, and A. M. Soto, "The male mammary gland: a target for the xenoestrogen bisphenol A," Reproductive Toxicology, vol. 37, pp. 15-23, 2013. 
[2] V. Bindhumol, K. C. Chitra, and P. P. Mathur, "Bisphenol A induces reactive oxygen species generation in the liver of male rats," Toxicology, vol. 188, no. 2-3, pp. 117-124, 2003.

[3] H. Kabuto, M. Amakawa, and T. Shishibori, "Exposure to bisphenol A during embryonic/fetal life and infancy increases oxidative injury and causes underdevelopment of the brain and testis in mice," Life Sciences, vol. 74, no. 24, pp. 2931-2940, 2004.

[4] C. Prahalathan, E. Selvakumar, and P. Varalakshmi, "Remedial effect of DL-alpha-lipoic acid against adriamycin induced testicular lipid peroxidation," Molecular and Cellular Biochemistry, vol. 267, no. 1-2, pp. 209-214, 2004.

[5] L. Peyre, P. Rouimi, G. de Sousa et al., "Comparative study of bisphenol $\mathrm{A}$ and its analogue bisphenol $\mathrm{S}$ on human hepatic cells: a focus on their potential involvement in nonalcoholic fatty liver disease," Food and Chemical Toxicology, vol. 70, pp. 9-18, 2014.

[6] F. R. Boockfor and C. A. Blake, "Chronic administration of 4-tert-octylphenol to adult male rats causes shrinkage of the testes and male accessory sex organs, disrupts spermatogenesis, and increases the incidence of sperm deformities," Biology of Reproduction, vol. 57, no. 2, pp. 267-277, 1997.

[7] K. C. Chitra, C. Latchoumycandane, and P. P. Mathur, "Induction of oxidative stress by bisphenol $\mathrm{A}$ in the epididymal sperm of rats," Toxicology, vol. 185, no. 1-2, pp. 119-127, 2003.

[8] M. Aydoğan and N. Barlas, "Effects of maternal 4-tertoctylphenol exposure on the reproductive tract of male rats at adulthood," Reproductive Toxicology, vol. 22, no. 3, pp. 455-460, 2006.

[9] A. Atkinson and D. Roy, "In vivo DNA adduct formation by bisphenol A," Environmental and Molecular Mutagenesis, vol. 26, no. 1, pp. 60-66, 1995.

[10] S. Suárez, R. A. Sueiro, and J. Garrido, "Genotoxicity of the coating lacquer on food cans, bisphenol A diglycidyl ether (BADGE), its hydrolysis products and a chlorohydrin of BADGE," Mutation Research-Genetic Toxicology and Environmental Mutagenesis, vol. 470, no. 2, pp. 221-228, 2000.

[11] H. A. A. Aly and Ò. Domènech, "Cytotoxicity and mitochondrial dysfunction of 2,3,7,8-tetrachlorodibenzo-p-dioxin (TCDD) in isolated rat hepatocytes," Toxicology Letters, vol. 191, no. 1, pp. 79-87, 2009.

[12] H. Inoue, A. Tsuruta, S. Kudo et al., "Bisphenol a glucuronidation and excretion in liver of pregnant and nonpregnant female rats," Drug Metabolism and Disposition, vol. 33, no. 1, pp. 55-59, 2005.

[13] J. B. Knaak and L. J. Sullivan, "Metabolism of bisphenol A in the rat," Toxicology and Applied Pharmacology, vol. 8, no. 2, pp. 175-184, 1966.

[14] T. Iso, T. Watanabe, T. Iwamoto, A. Shimamoto, and Y. Furuichi, "DNA damage caused by bisphenol A and estradiol through estrogenic activity," Biological and Pharmaceutical Bulletin, vol. 29, no. 2, pp. 206-210, 2006.

[15] D. G. Westbrook, P. G. Anderson, K. E. Pinkerton, and S. W. Ballinger, "Perinatal tobacco smoke exposure increases vascular oxidative stress and mitochondrial damage in non-human primates," Cardiovascular Toxicology, vol. 10, no. 3, pp. 216-226, 2010.

[16] M. R. Lee, H. Park, S. Bae et al., "Urinary bisphenol A concentrations are associated with abnormal liver function in the elderly: a Repeated Panel Study," Journal of Epidemiology and Community Health, vol. 68, no. 4, pp. 312-317, 2014.
[17] I. A. Lang, T. S. Galloway, A. Scarlett et al., "Association of Urinary Bisphenol A concentration with medical disorders and laboratory abnormalities in adults," Journal of the American Medical Association, vol. 300, no. 11, pp. 1303-1310, 2008.

[18] P. Kovacic, "How safe is bisphenol A? Fundamentals of toxicity: metabolism, electron transfer and oxidative stress," Medical Hypotheses, vol. 75, no. 1, pp. 1-4, 2010.

[19] J.-H. Lee, Y.-C. Li, S.-W. Ip et al., "The role of $\mathrm{Ca}^{2+}$ in baicaleininduced apoptosis in human breast MDA-MB-231 cancer cells through mitochondria- and caspase-3-dependent pathway," Anticancer Research, vol. 28, no. 3, pp. 1701-1711, 2008.

[20] L. You, M. Casanova, S. Archibeque-Engle, M. Sar, L.-Q. Fan, and H. D. A. Heck, "Impaired male sexual development in perinatal Sprague-Dawley and Long-Evans hooded rats exposed in utero and lactationally to $p, p^{\prime}$-DDE," Toxicological Sciences, vol. 45 , no. 2, pp. $162-173,1998$.

[21] K. Yamasaki, H. Okuda, T. Takeuchi, and Y. Minobe, "Effects of in utero through lactational exposure to dicyclohexyl phthalate and p, $\mathrm{p}^{\prime}$-DDE in Sprague-Dawley rats," Toxicology Letters, vol. 189, no. 1, pp. 14-20, 2009.

[22] M. L. Meistrich, P. K. Trostle, M. Frapart, and R. P. Erickson, "Biosynthesis and localization of lactate dehydrogenase $\mathrm{X}$ in pachytene spermatocytes and spermatids of mouse testes," Developmental Biology, vol. 60, no. 2, pp. 428-441, 1977.

[23] M. Orlowski and A. Meister, "Isolation of gamma-glutamyl transpeptidase from hog kidney," The Journal of Biological Chemistry, vol. 240, pp. 338-347, 1965.

[24] S. Reitman and S. Frankel, "A colorimetric method for the determination of serum glutamic oxalacetic and glutamic pyruvic transaminases," American Journal of Clinical Pathology, vol. 28, no. 1, pp. 56-63, 1957.

[25] M. K. Holland and B. T. Storey, "Oxygen metabolism of mammalian spermatozoa. Generation of hydrogen peroxide by rabbit epididymal spermatozoa," Biochemical Journal, vol. 198, no. 2, pp. 273-280, 1981.

[26] J. Hogberg, R. E. Larson, A. Kristoferson, and S. Orrenius, "NADPH dependent reductase solubilized from microsomes by peroxidation and its activity," Biochemical and Biophysical Research Communications, vol. 56, no. 3, pp. 836-842, 1974.

[27] A. K. Sinha, "Colorimetric assay of catalase," Analytical Biochemistry, vol. 47, no. 2, pp. 389-394, 1972.

[28] S. Marklund and G. Marklund, "Involvement of the superoxide anion radical in the autoxidation of pyrogallol and a convenient assay for superoxide dismutase," European Journal of Biochemistry, vol. 47, no. 3, pp. 469-474, 1974.

[29] D. E. Paglia and W. N. Valentine, "Studies on the quantitative and qualitative characterization of erythrocyte glutathione peroxidase," The Journal of Laboratory and Clinical Medicine, vol. 70, no. 1, pp. 158-169, 1967.

[30] M. Wu, H. Xu, Y. Shen, W. Qiu, and M. Yang, "Oxidative stress in zebrafish embryos induced by short-term exposure to bisphenol A, nonylphenol, and their mixture," Environmental Toxicology and Chemistry, vol. 30, no. 10, pp. 2335-2341, 2011.

[31] P. Murugesan, T. Muthusamy, K. Balasubramanian, and J. Arunakaran, "Studies on the protective role of vitamin $\mathrm{C}$ and E against polychlorinated biphenyl (Aroclor 1254)—induced oxidative damage in Leydig cells," Free Radical Research, vol. 39, no. 11, pp. 1259-1272, 2005. 
[32] P. Vernet, R. J. Aitken, and J. R. Drevet, "Antioxidant strategies in the epididymis," Molecular and Cellular Endocrinology, vol. 216, no. 1, pp. 31-39, 2004.

[33] H. Yokota, H. Iwano, M. Endo et al., "Glucuronidation of the environmental oestrogen bisphenol A by an isoform of UDPglucuronosyltransferase, UGT2B1, in the rat liver," Biochemical Journal, vol. 340, no. 2, pp. 405-409, 1999.

[34] A. Atkinson and D. Roy, "In vitro conversion of environmental estrogenic chemical bisphenol A to DNA binding metabolite(s)," Biochemical and Biophysical Research Communications, vol. 210, no. 2, pp. 424-433, 1995.

[35] S. R. Plymate, K. H. Haugk, C. C. Sprenger et al., "Increased manganese superoxide dismutase (SOD-2) is part of the mechanism for prostate tumor suppression by Mac25/insulin-like growth factor binding-protein-related protein-1," Oncogene, vol. 22, no. 7, pp. 1024-1034, 2003.

[36] I. E. Touahar, L. Haroune, S. Ba, J.-P. Bellenger, and H. Cabana, "Characterization of combined cross-linked enzyme aggregates from laccase, versatile peroxidase and glucose oxidase, and their utilization for the elimination of pharmaceuticals," Science of the Total Environment, vol. 481, no. 1, pp. 90-99, 2014.

[37] C. A. Burtis, E. R. Ashwood, and D. E. Bruns, Tietz Fundamentals of Clinical Chemistry, Saunders, 2001.

[38] B.-E. Lee, H. Park, Y.-C. Hong et al., "Prenatal bisphenol A and birth outcomes: MOCEH (Mothers and Children's Environmental Health) study," International Journal of Hygiene and Environmental Health, vol. 217, no. 2-3, pp. 328-334, 2014.

[39] H. A. A. Aly and R. M. Khafagy, "2,3,7,8-tetrachlorodibenzo-pdioxin (TCDD)-induced cytotoxicity accompanied by oxidative stress in rat Sertoli cells: possible role of mitochondrial fractions of Sertoli cells," Toxicology and Applied Pharmacology, vol. 252, no. 3, pp. 273-280, 2011.

[40] M. E. Guicciardi and G. J. Gores, "Apoptosis: a mechanism of acute and chronic liver injury," Gut, vol. 54, no. 7, pp. 1024-1033, 2005.

[41] D. R. Green and G. Kroemer, "The pathophysiology of mitochondrial cell death," Science, vol. 305, no. 5684, pp. 626-629, 2004.

[42] Å. B. Gustafsson and R. A. Gottlieb, "Bcl-2 family members and apoptosis, taken to heart," American Journal of Physiology: Cell Physiology, vol. 292, no. 1, pp. C45-C51, 2007.

[43] B. Antonsson, F. Conti, A. Ciavatta et al., "Inhibition of Bax channel-forming activity by Bcl-2," Science, vol. 277, no. 5324, pp. 370-372, 1997. 

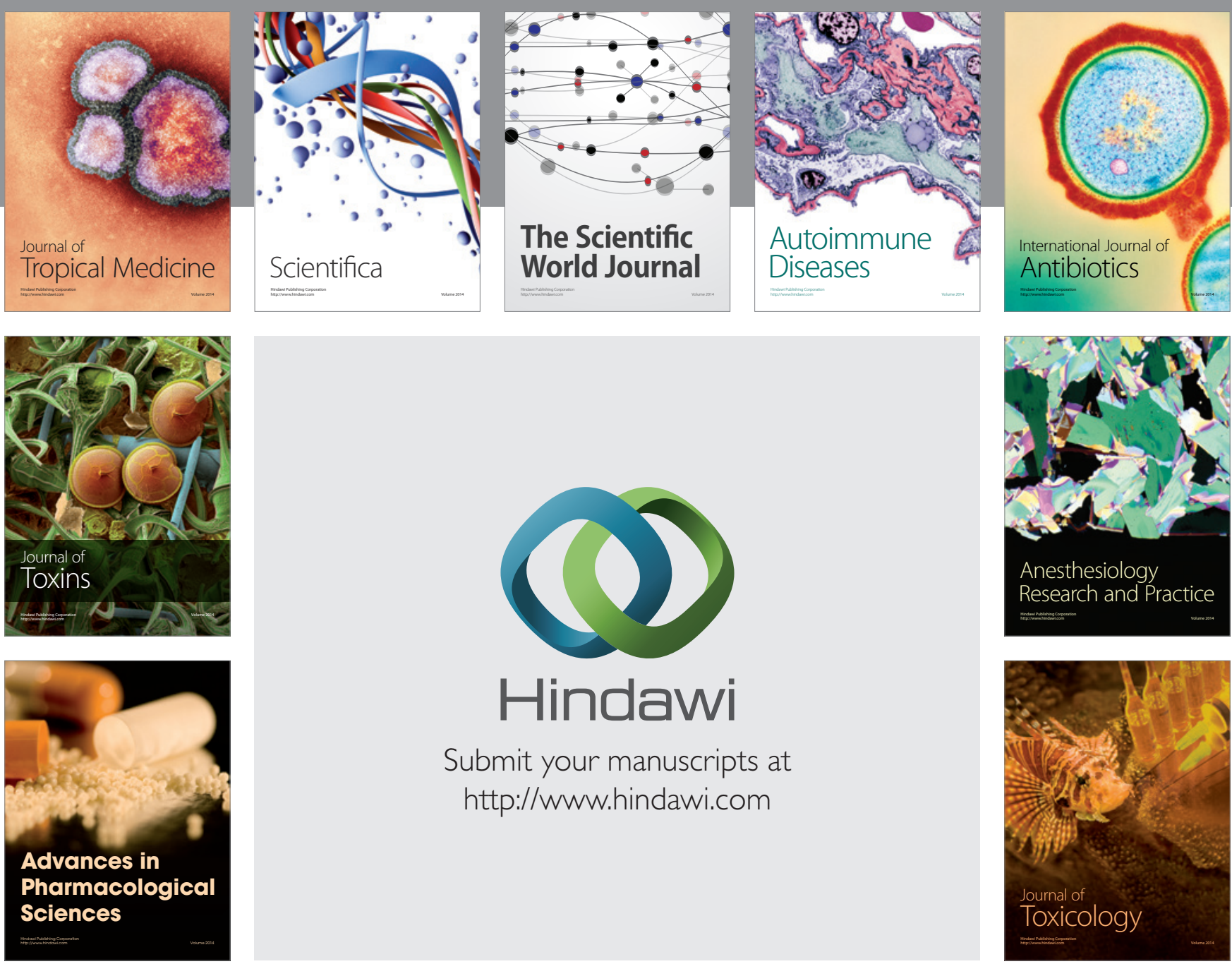

\section{Hindawi}

Submit your manuscripts at

http://www.hindawi.com
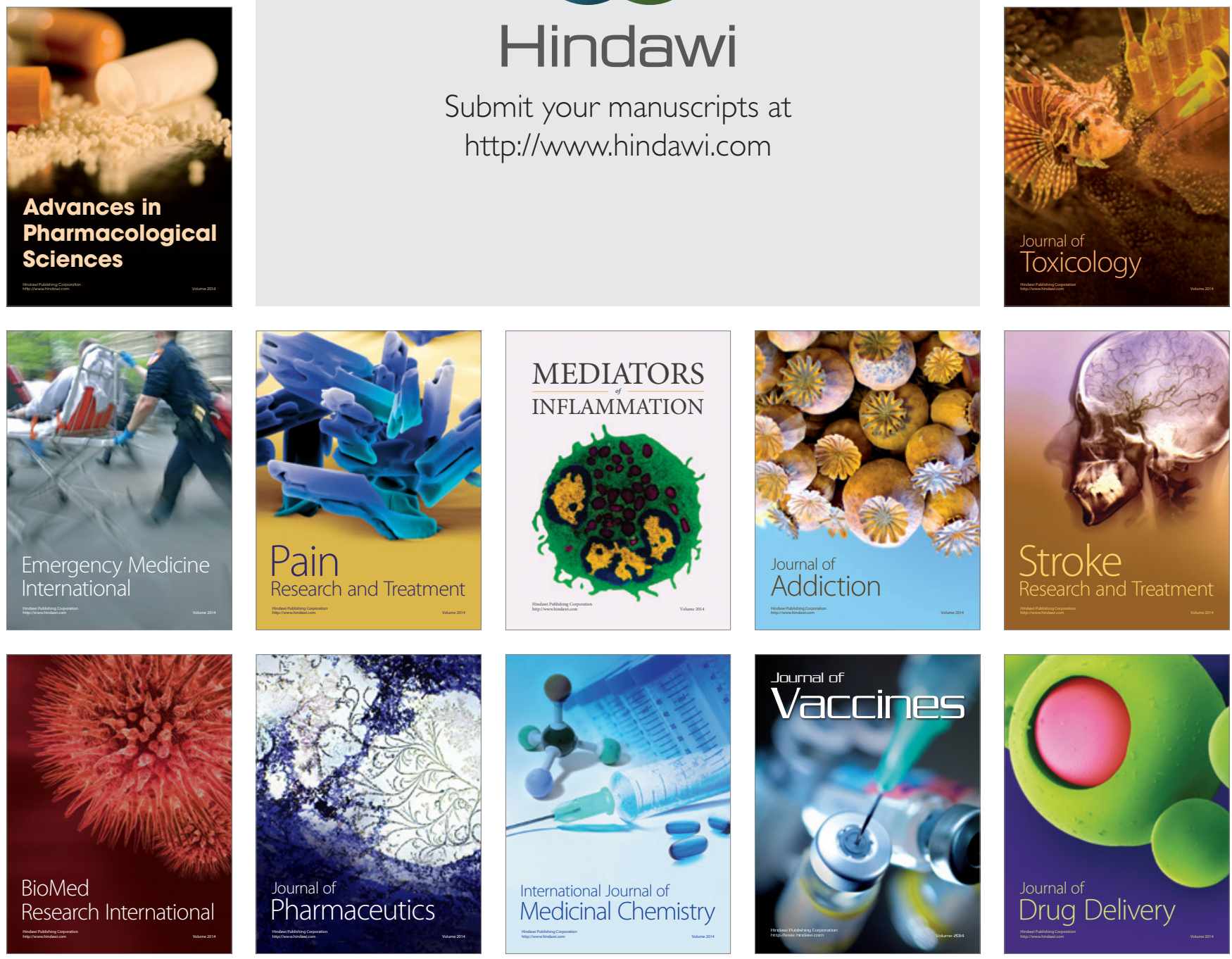